\title{
PRODUCT LIFECYCLE FORECASTING USING SYSTEM'S INDICATORS
}

\author{
Rehar, T. ; Ogrizek, B..$^{* *}$; Leber, M. ${ }^{* * *}$; Pisnik, A. ${ }^{* * * *} \&$ Buchmeister, B. ${ }^{* * *}$ \\ * Gorenje d.d., Partizanska 12, 3320 Velenje, Slovenia \\ *** BSH Home Appliances, Savinjska 30, 3331 Nazarje, Slovenia \\ *** University of Maribor, Faculty of Mechanical Engineering, Smetanova 17, 2000 Maribor, Slovenia \\ ${ }^{* * * *}$ University of Maribor, Faculty of Economics and Business, Razlagova 14, 2000 Maribor, Slovenia \\ E-Mail: tomaz.rehar@gorenje.com, bostjan.ogrizek@bshg.com, marjan.leber@um.si, \\ aleksandra.pisnik@um.si, borut.buchmeister@um.si
}

\begin{abstract}
The concept of product lifecycle is one of the tools of strategic management and gives a company the guidelines for marketing their product. It is very important that companies know in which lifecycle stage their product is. When conceiving a product platform, companies rely on the researches of socioeconomic parameters. These parameters are called influence parameters, because by changing through time they influence the sales of the product and consequently the lifecycle curve, and require the company to change its business model, business strategy or their product. The changes of influence parameters reflect the changes of consumer needs, which is why in most cases the product needs to be adapted to the new parameters. In order for companies to know in which lifecycle stage the product is or will be, they often use forecasting methods. In this process, all the socio-economic parameters are projected that were valid in that specific period. The purpose of the article is to develop a model that takes into account the changing of influence parameters and gives reliable medium-term forecasts of the sales of a given product (attached is an example of a built-in oven lifecycle).

(Received in April 2016, accepted in November 2016. This paper was with the authors 2 months for 1 revision.)
\end{abstract}

Key Words: Product Lifecycle, Simulation, Forecasting, Mathematical Modelling, System's Indicators

\section{INTRODUCTION}

A product lifecycle can be defined as demand for the product or the scope of sales in time. The time of presence of the product on the market depends largely on the factors that impact the sales of the product. A product's lifecycle is graphically represented by an " $\mathrm{S}$ " curve that is determined by influence parameters. The latter are different on different markets and change through time, just like the trends change. In the stage of introducing a product on the market, the costs are the highest, as companies need to invest in market research, product conception and development, new production technologies, marketing and the development of a sales network. Product conception is the first stage in the development process and is of key significance, having a major impact on whether or not the product will achieve the set objectives [1]. Therefore, the conception of a platform for a multi-generation product (MGP) requires clear starting points that are called influence parameters. They change throughout the lifecycle of the product, so the product needs to be modified through time. In developing a new generation of a MGP we use starting points, i.e. new influence parameters valid at that moment. This way the new product placed on the market is contemporary and fits the current global trends. Companies that prepare and introduce a new generation of MGP early enough have competitive advantage. That is why they need reliable forecasts of sales fluctuation for a certain product platform. Companies use diffusion simulation models based on data on the sales of the past generation of products sold on the market. The models project the sales patterns of the previous generation to the sales of the future generation. If we want to simulate 
the lifecycle of a new product, we need to compare the influence parameters that we took into account in developing the original model of the product with the ones that are currently valid.

\section{LITERATURE REVIEW}

The level of innovation in the world is quite extensive, which is reflected in a large number of start-up projects. Products that were under laboratory research a decade ago are nowadays largely represented on the market. An ideal new product is a new invention that has never been seen before and meets the needs that have never been met yet. However, companies with a tradition based on good and tested products update them through time and offer their updated versions to buyers [2,3]. This strategy is called the multi-generation product strategy. The same approach is also used in Gorenje Group, where good products are being upgraded with new characteristics. In articles [4-8] several authors explain the multi-generation product strategy (MGPS), in accordance with which the company first launches the first generation of products on the market. After the initial launch, the company gradually introduces new generations throughout a longer period of time, where the basic features remain the same, and the product is upgraded with modern technologies, characteristics, design and usability [5-7]. The use of this strategy enables companies to prolong the life span of the product from one product to a line of products and releasing the necessary time for their development. This way the companies can better use their resources and technologies to design better products and acquire better opportunities for long-term success [8].

Nowadays the development of innovations is based on a large feedback loop, where technological development is interacting with social and market models and requirements. Constant innovations cyclically generate new social and market needs, new competition and new technological development. Innovative models try to keep the sales at the desired level of the "S" form of the lifecycle curve [9].

The existing quantitative models of MGP can be roughly divided into two types: behavioural models and competition dynamic models. Behavioural models attempt to simulate or explain the behaviour of MGP. One of the first behaviour models is based on the use of the Bass diffusion model. Norton and Bass [10] used the Bass diffusion model to study the sales behaviour of high-technology MGP. The authors suggest a model that takes into account that requirements are diffused through time and that a new, next generation of products irrevocably replaces the existing one. The model can be used for forecasting future changes in the demand for the entire sales of MGP. All these models are usually based on previous sales numbers, which makes it very difficult to foresee the diffusion of a new product merely based on some items of data. So the majority of published models for forecasting the introduction of new products on the market is focussed on describing the diffusion pattern or, in the best case, short-term forecasts can be generated [11].

For a long time, researchers have been trying to develop a good forecasting model for newly developed products. There are many methods for forecasting the lifecycle of a new product that can be divided into three categories:

1. Analogue approach [12-14], where the forecaster assumes that the new product will behave very similarly to the comparable products on the market.

2. Subjective approach $[14,15]$, where past sales experience is used.

3. Market approach $[16,17]$, where before the launch of the project, the forecaster conducts a survey among the buyers to receive data that they need to perform a simulation.

Competitive advantage of companies is not merely based on the innovation of products, based on R\&D work, but also on the technical and non-technical (organisational) innovations with which we want to modernise products and production processes $[18,19]$. That is why the lifecycle curve of products is shortening. The increasing market complexity and the 
increasing product complexity make product sales forecasting difficult [20, 21]. The most important thing in forecasting is to take into account the buyers' view on the market and not the companies' view [22].

Diffusion models describe the dependency on the sales of new products or services in relation to time. The Bass model is based on the interaction among the users and potential users that influence the process of approving new products or services. Bass divides them into two categories of users:

- Innovators. This category involves users that have a desire for new services or technologies (without the influence of other users). This category of users is affected by marketing and advertising intensity. The impact of innovators is marked by innovation parameter $p$.

- Imitators or copiers. This category represents the basis of expanding the innovation and is directly dependent on the number of users that have already accepted new services or technologies. The exchange of experience among users impacts the number of imitators, whose impact is shown in the imitation parameter $q$.

Parameters $p$ and $q$ determine the level and form of the curve's growth, described by $F(t)$. The Bass model suggests that potential buyers are influenced by two types of advertising communication: mass media and interpersonal communications. One group of buyers decides to buy a certain product based on advertising in mass media (external influence) and the other group of buyers decides based on interpersonal communication (internal influence) [23]. Using the Bass model for forecasting that encourages innovation [24], requires the estimation of three parameters: external influence coefficient $(p)$, internal influence coefficient $(q)$ and market potential $(m)$. The estimation of these parameters depends on the quantity of available data. We know the following types of estimation [23]:

- Without previous data: if data is unavailable, parameter estimations can be acquired based on the diffusion of similar products. These values can simply be determined from previous comparative technologies.

- Estimation with available data: The Bass model is formed according to the analogy of historical data of expanding similar technology (older generation). The newest technology is basically the same as previous technology. If data is available, we need information about a minimum of three periods. Stable and reliable parameter estimations for the Bass model are appropriate only if the peak was already reached. The point where the growth curve slows down needs to have occurred already; otherwise the Bass model cannot be calculated. When data is available, one of the first procedures for estimating the diffusion of parameters is the least squares estimate, which was also used to calculate the $p, q$ and $m$ parameters. This procedure includes the estimation of parameters by using regression analysis.

The Bass model is designed based on the assumption that the potential possibility that a randomly selected individual will start using a service in time $t$ is linearly dependent on the number of individuals that have already decided to use the service. These linear coefficients are related to the characteristics of innovation and imitation. The probability that someone might accept a new product or service in time $t$ with the assumption that the user has not yet accepted the product or service, can be expressed with the following formula [25]:

$$
\frac{f(t)}{1-F(t)}=p+\frac{q}{m} Y(t)
$$

$f(t)$ - percentage of users that decide to use a service in the moment $t$,

$F(t)$ - cumulative percentage of users that have already accepted a service by the time $t$,

$p$ - innovation coefficient,

$q-$ imitation coefficient,

$m \quad-$ number of individuals that will accept the service in the long term,

$Y(t)$ - number of individuals that have already decided to use the service by the moment $t$. 
The rate of adoption $S(t)$ in time $t$ can be calculated using the following formula [25]:

$$
S(t)=p m+(q-p) Y(t)-\frac{q}{m} Y(t)^{2}
$$

The adoption rate can be explained as the number of individuals that at a certain point decide to use a service. The Eq. (2) can be adjusted [25]:

where:

$$
S(t)=a+b Y(t-1)+c[Y(t-1)]^{2}
$$

$$
a=p m ; \quad b=p-q ; c=-\frac{q}{m}
$$

In such a form, we can use it to estimate parameters $a, b$ and $c$ with regression analysis according to the least squares method. The parameters of Bass model $m, p$ and $q$ can be acquired by solving [25]:

$$
m=\frac{-b \pm \sqrt{b^{2}-4 a c}}{2 c} ; \quad p=\frac{a}{m} ; \quad q=-m c
$$

Time when the highest rate of adoption occurs $S(t)$, can be calculated with the following formula [25]:

$$
t^{*}=\frac{1}{p+q} \ln \frac{q}{p}
$$

Using the Eq. (2) we then calculate the values for each time period separately and show them in the form of a diagram, where they form a curve that simulates the product's lifecycle.

\section{SYSTEM INDICATORS THAT IMPACT THE LIFECYCLE CURVE}

With single-generation products (SGP), companies adapt or add new characteristics and technologies to the products, while the products remain more or less the same. In the case of MGP they launch new product that has completely new features and technologies and is also differently designed or adapted to the situation and needs of the market. Already in the conception stage of the new product or platform, it is extremely important for a company to have correct data on the economic, market and social situation on the market. New products on a new platform are conceived for a longer period of time or for a specific quantity of products that economically justifies the new platform. That is why it is very important to know what the starting point of the company is in the platform conception stage. It is important for a company to acquire as many influence parameters as possible that impact the product sales and, as a consequence, the lifecycle curve. Influence parameters change through time, so the new platforms must be conceived in such a way that the parameter changes do not influence the change of platform during the amortisation period.

\subsection{Influence parameters}

Influence parameters include the values of statistical data, socio-economic data and marketing activities. Influence parameters are very interconnected and interdependent. If we see the world as a global market, we can find influence parameters that are the same for all markets. Due to different socio-economic situations on different markets, the influence parameter values also differ. Parameters that impact the lifecycle curve are very varied and can be divided according to impact areas. Thus we distinguish market parameters, buyer parameters, product parameters, function parameters, marketing parameters and company parameters. They are described more into detail in chapter 6 . If influence parameters are valid for the local level, we can potentially project these parameters to larger areas, such as countries and regions. So we can use the same parameters to describe the impacts on the lifecycle curve on the local as well as the global level. 


\subsection{Influence factor}

Influence factor is a piece of information that tells us how great the difference is between the current and initial state of an individual group of influence parameters (Fig. 1). Influence parameters represent variables that impact the function of the product lifecycle curve.

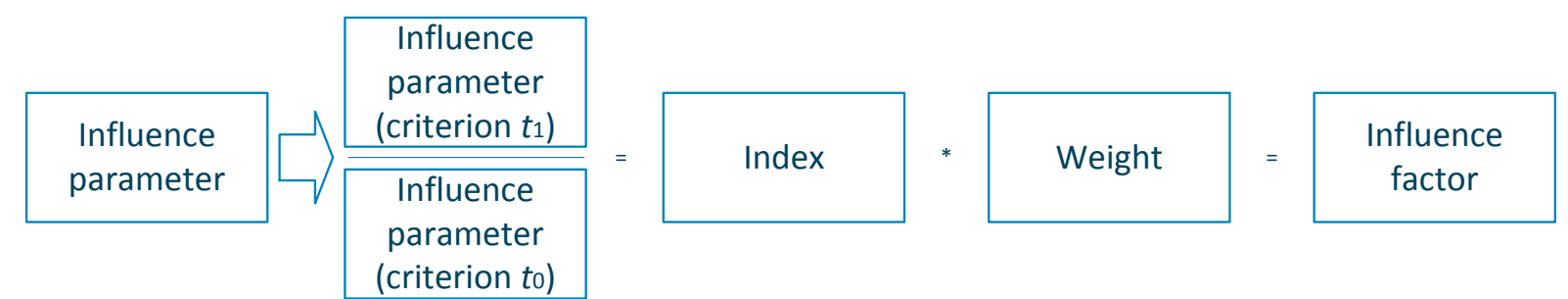

Figure 1: Flowchart - calculating the influence factor.

If we compare the same influence parameters in time $t_{0}$ (time of platform conception) and in time $t_{1}$ (now), we can see that the influence parameters differ. We will make the comparison with relative numbers, i.e. indexes. The index is calculated by dividing the current influence parameter at $t_{1}$ with the initial, i.e. basic influence parameter at $t_{0}$, formula (7). Thusly calculated index will be called the influence index:

$$
I_{v}=\frac{P\left(t_{1}\right)}{P\left(t_{0}\right)}
$$

where:

$I_{v} \quad$ - influence index,

$P\left(t_{0}\right) \quad$ - influence parameter at $t_{0}$,

$P\left(t_{1}\right) \quad$ - influence parameter at $t_{1}$.

As not all influence factors have the same influence on the lifecycle curve, we need to determine the weights that are equivalent to their impact. This is how we acquire weighted influence indexes.

where:

$$
I_{u t}=I_{v} * U
$$

$I_{u t}-$ weighted influence index,

$I_{v}$ - influence index,

$U$ - weight.

All influence indexes together form the influence factor. Influence factors are calculated using the following formula (9):

where:

$$
F_{v}=\frac{\sum I_{u t}}{\sum U_{i}}
$$

$F_{v}$ - influence factor,

$I_{u t}$ - weighted influence index,

$U_{i}-$ weight.

\subsection{Factor upgrade of the Bass model}

Bass's model assumes that innovators buy a product under the influence of marketing and are also those that inspire imitators to buy the same product. The Bass model requires past data for the calculation of the diffusion factor, based on which it is possible to use the model formula to calculate the movement of the lifecycle curve. Due to using the past data, we project also the economic, social and market situation from the past into the model for lifecycle curve forecasting. These are transferred into diffusion factors which we can use to 
simulate the movement of the lifecycle curve for a new product in the coming years. This is why we upgraded the Bass model with factors that take into account the changes of influence parameters through time.

Influence factors correct the result of the Bass model and take into account the changes of socio-economic and other parameters that impact the lifecycle curve. The new formula is:

where:

$$
S\left(t_{1}\right)^{\prime}=\left(a+b Y(t-1)+c[Y(t-1)]^{2}\right) *\left(\frac{\sum F_{i} * U_{i}}{\sum U_{i}}\right)
$$

$S\left(t_{1}\right)$ - rate of adoption in time $t_{1}$,

$F_{i} \quad$ - influence factor,

$U_{i} \quad$ - weight of the influence factor.

Eq. (10) for the simulation of the lifecycle curve was tested on the NG3 platform. To simulate the lifecycle curve for the sales of the NG3 ovens stage 2 (NG3 F2) the sales data for the NG3 ovens stage 1 (NG3 F 1) was used (Table I), corrected with influence factors. The calculated curve of the lifecycle was compared to the real data from 2015 and 2016. Based on the findings we can give recommendations about whether the existing platform is still interesting for the buyers and when it is advisable to start introducing a new platform.

\section{CASE: NG3 PLATFORM}

In Gorenje we have been producing ovens and stoves ever since the company was established. They are one of the company's most important products. To meet the need for mid-price ovens we developed the NG3 platform in 2007. The platform can be defined as the basis that enables the production of a family of products with certain common features. Products made on the same platform share the same basic components, but can completely differ and have different user characteristics. Companies use this very often, as adapting the products to the buyers makes them become very flexible and able to use the same platform to adjust the products at a small cost and with great speed to the needs on the market. This ensures a high level of automatization of the basic key product components, improving the price efficiency of the entire platform. Built-in ovens of the NG3 platform (Fig. 2) represent $85 \%$ of all builtin ovens produced by Gorenje.

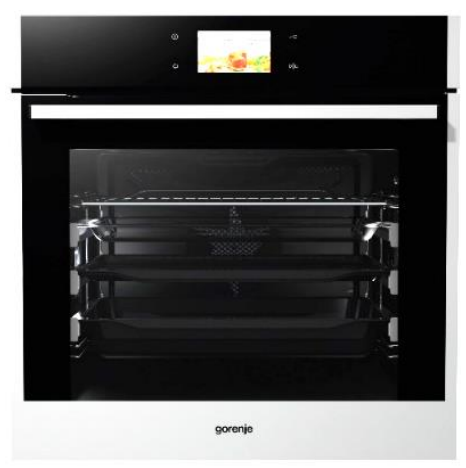

Figure 2: Built-in oven NG3.

\subsection{Sales of built-in ovens NG3}

Built-in ovens NG3 are global products, as they are being sold in over 70 countries in the world. The main market is still Europe, as over $60 \%$ of all the appliances produced on the NG3 platform is sold there. The second largest market is the Asian market, where we have, especially due to the immense population, great potential that we haven't taken advantage of yet. 
The data on the sales of appliances are of key importance for the simulation, because they are the basis for calculating $m, p$ and $q$. The data on the sales of built-in ovens NG3 were acquired from the marketing service.

In 2014 the NG3 platform was upgraded with new improvements, features and technologies. For the needs of the simulation of the lifecycle curve of the NG3 F2 appliances, we wanted to know how many NG3 F1 and how many NG3 F2 appliances have already been sold and where. The transition between the two stages is still in progress, as can be seen in Fig. 3. NG3 F2 is gradually replacing NG3 F1. It appears that due to price policy and design, F1 will not be completely replaced - the production of F1 will continue, but in very small quantities. Table I show the sales of NG3 appliances on the Slovenian market.

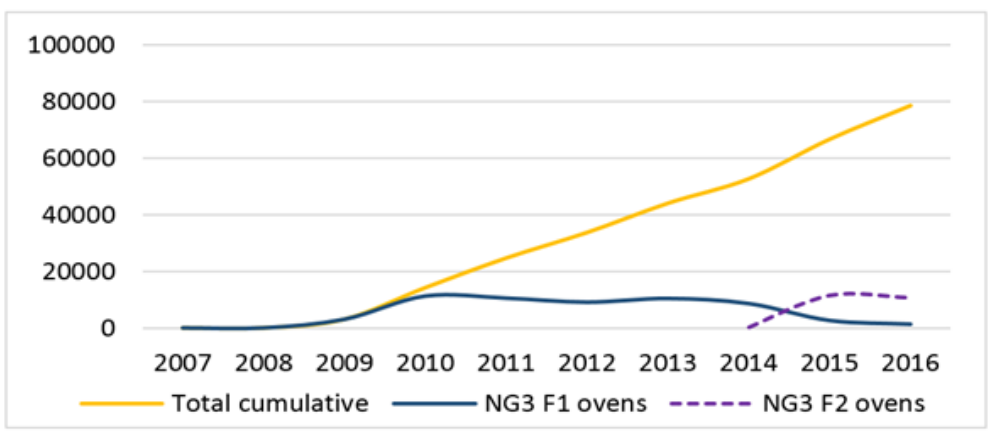

Figure 3: NG3 sales from 2007 to 2016.

Table I: Data on the sales of NG3 2007-2015.

\begin{tabular}{|c|c|c|c|c|}
\hline Year & Sales of NG3 F1 [pcs.] & Sales of NG3 F2 [pcs.] & Total [pcs.] & Cumulative [pcs.] \\
\hline 2007 & 0 & & 0 & 0 \\
\hline 2008 & 23 & & 23 & 23 \\
\hline 2009 & 3030 & & 3030 & 3053 \\
\hline 2010 & 11175 & & 11175 & 14228 \\
\hline 2011 & 10450 & & 10450 & 24678 \\
\hline 2012 & 9030 & & 9030 & 33708 \\
\hline 2013 & 10337 & & 10337 & 44045 \\
\hline 2014 & 8537 & 78 & 8615 & 52660 \\
\hline 2015 & 2613 & 11386 & 13999 & 66659 \\
\hline 2016 & 1315 & 10557 & 11872 & 78531 \\
\hline
\end{tabular}

Based on the sales data from Table I the Microsoft Excel programme was used to model a lifecycle curve for the NG3 product.

\subsection{Determining the values of influence parameters, indexation and calculating the influence}

Indexation of influence parameters can only be carried out after sorting the data on values of influence parameters according to criteria. Eq. (7) is used. In Tables II and III we collected 40 influence parameters of the market, buyer, product, function, marketing and influence parameters of the company. After calculating the values of indexes, we must determine the level of influence on the product lifecycle curve for each influence parameter. Weights for individual families of influence parameters are calculated using an online programme for calculating weights using the analytical hierarchy process or AHP [26]. For each influence parameter in the family of parameters, we need to make a pair comparison to determine which parameter has a bigger impact on the sales of the NG3 products. Based on a decision matrix, the programme calculates the rank and weight that each influence parameter has on the sales of the products. The weights of individual indexes are given in Table II. 
Rehar, Ogrizek, Leber, Pisnik, Buchmeister: Product Lifecycle Forecasting Using System's ...

Table II: Calculation of indexes and weights of influence parameters.

\begin{tabular}{|c|c|c|c|c|}
\hline Market influence parameter & Value in $2008\left(t_{0}\right)$ & Value in $2015\left(t_{1}\right)$ & Index & Weight \\
\hline Country's purchasing power - GDP $[€]$ & 18769 & 18693 & 0,9960 & 0,326 \\
\hline Size of country $\left[\mathrm{km}^{2}\right]$ & 20273 & 20273 & 1,0000 & 0,02 \\
\hline Number of citizens $\left[10^{6}\right]$ & 2,021 & 2,063 & 1,0208 & 0,095 \\
\hline Economic growth [\%] & 3,3 & 2,3 & 0,6970 & 0,124 \\
\hline Inflation rate [\%] & 5,7 & 0,2 & 0,0351 & 0,119 \\
\hline Average monthly net salary [€] & 938 & 1035,58 & 1,1040 & 0,157 \\
\hline Level of unemployment [\%] & 4,9 & 9,8 & 2,0000 & 0,056 \\
\hline Average population age [years] & 41,1 & 42,5 & 1,0341 & 0,057 \\
\hline Prices of electric energy $[€]$ & 114,07 & 155,16 & 1,36 & 0,045 \\
\hline \multicolumn{5}{|l|}{ Buyer influence parameter } \\
\hline Average age [years] & 41 & 43 & 1,0488 & 0,076 \\
\hline Gender [\% women] & 51 & 50 & 0,9804 & 0,102 \\
\hline Demanding in terms of details & 2 & 4 & 2,0000 & 0,364 \\
\hline Brand recognition on the market & 5 & 5 & 1,0000 & 0,178 \\
\hline $\begin{array}{l}\text { Experience in using the products of the } \\
\text { brand }\end{array}$ & 4 & 4 & 1,0000 & 0,134 \\
\hline Brand trust & 4 & 3 & 0,7500 & 0,146 \\
\hline \multicolumn{5}{|l|}{ Product influence parameter } \\
\hline Technological sophistication of the product & 2 & 3 & 1,5000 & 0,04 \\
\hline Materials used & 3 & 3 & 1,0000 & 0,059 \\
\hline Design & 3 & 2 & 0,6667 & 0,163 \\
\hline Price & 2 & 3 & 1,5000 & 0,276 \\
\hline Level of recall on the market [\%] & 0,1 & 0,04 & 0,6000 & 0,302 \\
\hline Ergonomics & 3 & 4 & 1,3333 & 0,062 \\
\hline Simplicity of use & 3 & 4 & 1,3333 & 0,098 \\
\hline \multicolumn{5}{|l|}{\begin{tabular}{|l|} 
Function influence parameter \\
\end{tabular}} \\
\hline Function reliability & 2 & 3 & 1,5000 & 0,487 \\
\hline Number of programmes & 6 & 10 & 1,6667 & 0,219 \\
\hline Smart connection with other appliances & 1 & 1 & 1,0000 & 0,037 \\
\hline Useful value of the product & 3 & 4 & 1,3333 & 0,257 \\
\hline \multicolumn{5}{|l|}{ Marketing influence parameter } \\
\hline Intensity of advertising [€] & 250.000 & 400.000 & 1,6000 & 0,202 \\
\hline Advertising channels & 2 & 4 & 2,0000 & 0,098 \\
\hline Sponsorships & 150000 & 250000 & 1,6667 & 0,129 \\
\hline Success of sponsored groups & 3 & 5 & 1,6667 & 0,245 \\
\hline Brand value $\left[10^{6} €\right]$ & 445 & 530 & 1,19 & 0,045 \\
\hline 'Packaging' - marketing story & 3 & 3 & 1,00 & 0,151 \\
\hline Competition & 3 & 1 & 0,33 & 0,029 \\
\hline Target group & 3 & 3 & 1,00 & 0,037 \\
\hline \multicolumn{5}{|l|}{ Company influence parameter } \\
\hline Share value $[€]$ & 22,47 & 4,60 & 0,2047 & 0,026 \\
\hline Turnover $[€]$ & 1.330 .753 .000 & 1.225 .029 .000 & 0,9206 & 0,444 \\
\hline EBIT $\left[10^{6} €\right]$ & 36,90 & 34,40 & 0,9322 & 0,077 \\
\hline EBITDA $\left[10^{6} €\right]$ & 94,00 & 80,10 & 0,8521 & 0,081 \\
\hline EBITDA margin [\%] & 7,10 & 6,40 & 0,9014 & 0,081 \\
\hline Net profit or loss for the period $\left[10^{6} €\right]$ & 10,10 & $-8,00$ & $-0,7921$ & 0,291 \\
\hline
\end{tabular}


Influence factors were calculated using the Eq. (9). The values of factors are given in Table III. They speak volumes about the conditions that impact the sales of NG3 products. If we look at the market factor, we can see that the situation has deteriorated and that the number of buyers has decreased compared to 2008, which was considered the initial time. Additionally, buyers have become more demanding and want more sophisticated and quality appliances. They want more for their money and expect the product to justify their decision to purchase it.

Table III: Results of calculating influence factors.

\begin{tabular}{|l|c|}
\hline Influence factor & Value \\
\hline Market factor & 0,948 \\
\hline Buyer factor & 1,329 \\
\hline Function factor & 1,475 \\
\hline Product factor & 1,036 \\
\hline Marketing factor & 1,449 \\
\hline Company factor & 0,397 \\
\hline
\end{tabular}

Moreover, the function factor shows that the buyers find it important how the product performs its function and that the useful value of the product is at a high level. The product factor shows that the product's quality has remained the same as in the initial time, with some minor improvements. It is very obvious that the company invests in marketing, as the marketing factor is very high. But somehow this is not reflected in the company's business, as the company factor is very low. This means that the company's performance has dropped drastically since 2008 .

\subsection{Modelling the lifecycle curve for NG3 F2 appliances}

The basis for forecasting the lifecycle curve for NG3 F2 appliances is the curve for NG3 F1. From Table I we can see how the users adapted/adjusted to the novelty. If we want to use or project the sales characteristics from NG3 F1 to NG3 F2 and keep the same patterns for adopting new products, we need to take a look at the transition between the generations. As it is evident from Table I or Fig. 3, the transition occurred very quickly. In practically one year, the average annual sales quantity of NG3 was reached. That is why the level of adopting from the beginnings of NG3 F1 will not be correct. Considering the fact that the top of the sales curve was achieved somewhere in 2013, we can calculate the parameters by means of the regression analysis and use the period between 2009 and 2014, Table IV. With regression analysis we can calculate the necessary parameters, Table V.

Table IV: Basis for calculating regression analysis.

\begin{tabular}{|c|c|c|c|c|}
\hline Year $t$ & $\begin{array}{c}\text { Sales of NG3 } \\
\text { F1: } S(t)\end{array}$ & $\begin{array}{c}\text { Cumulative sales by } \\
\text { years: } N(t)\end{array}$ & $N(t-1)$ & $N(t-1)^{2}$ \\
\hline 2009 & 0 & 0 & 0 & 0 \\
\hline 2010 & 11175 & 14228 & 0 & 0 \\
\hline 2011 & 10430 & 24658 & 14228 & 202435984 \\
\hline 2012 & 9030 & 33688 & 24658 & 608016964 \\
\hline 2013 & 10337 & 44025 & 33688 & 1134881344 \\
\hline 2014 & 8537 & 52562 & 44025 & 1938200625 \\
\hline
\end{tabular}

The results of regression analysis necessary for calculating the factors $m, p$ and $q$ are shaded in Table V. These values are: Intercept (hereinafter: $a$ ), $X$ Variable $1(b), X$ Variable 2 $(c)$. 
According to Eqs. (5) we can calculate the parameters of the Bass model $m, p$ and $q$.

$$
\begin{aligned}
& p=\frac{a}{m}=\frac{5736,513223}{67294,2}=0,085 \quad m=\frac{-b \pm \sqrt{b^{2}-4 a c}}{2 c}=67294,2 \\
& q=-m c=-67294,2 *(-6,31593 \mathrm{E}-06)=0,4250
\end{aligned}
$$

Table V: Results of regression analysis.

\begin{tabular}{|c|c|c|}
\hline \multirow[t]{2}{*}{ ANOVA } & \multicolumn{2}{|r|}{ 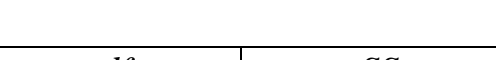 } \\
\hline & $d f$ & $S S$ \\
\hline Regression & 2 & 20978283,55 \\
\hline Residual & 3 & 65438565,95 \\
\hline Total & 5 & 86416849,5 \\
\hline & Coefficients & Standard Error \\
\hline Intercept & 5736,513223 & 3248,801031 \\
\hline$X$ Variable 1 & 0,339780552 & 0,396979752 \\
\hline$X$ Variable 2 & $-6,31593 E-06$ & $9,30933 \mathrm{E}-06$ \\
\hline
\end{tabular}

\begin{tabular}{|l|c|}
\hline Regression Statistics \\
\hline Multiple $R$ & 0,49270 \\
\hline$R$ Square & 0,24276 \\
\hline Adjusted $R$ Square & $-0,26207$ \\
\hline Standard Error & 4670,42346 \\
\hline Observations & 6 \\
\hline
\end{tabular}

\section{SIMULATION OF THE LIFECYCLE CURVE OF NG3 F2 BUILT-IN OVENS}

Using parameters $m, p$ and $q$ we first solve Eq. (2). The set of solutions for Eq. (2) for each year defines a curve that best describes the course of sales of the NG3 F1 appliances in the years in question. As forecasting the lifecycle curve of the NG3 F2 appliances is based on the parameters of the previous generation, the parameters $m, p, q$ were used in Eq. (10). The weights of influence factors (determined using the AHP method) are shown in Table VI. From the weights we can see that marketing and buyer are very interconnected and interdependent.

When we determine the weights of influence factors, we have all the data necessary for calculating the simulation of the lifecycle curve of NG3 F2 appliances. In Eq. (10) we use the parameters $m, p$, and $q$ and the values of influence factors and their weights. Based on these parameters we calculate the level of adoption by taking into account the socio-economic situation on the market. The results of the calculation of simulation of the sales of NG3 F2 appliances, using Eq. (10) are shown in Table VII.

Table VI: Results of the calculation of influence factors.

\begin{tabular}{|l|c|c|}
\hline Influence factor & Value & Weight \\
\hline Market factor & 0,948 & 0,202 \\
\hline Buyer factor & 1,329 & 0,294 \\
\hline Function factor & 1,475 & 0,082 \\
\hline Product factor & 1,036 & 0,113 \\
\hline Marketing factor & 1,449 & 0,277 \\
\hline Company factor & 0,397 & 0,032 \\
\hline
\end{tabular}

Table VII: Results of the calculation of simulation of the sales of NG3 F2 appliances.

\begin{tabular}{|c|c|c|}
\hline Year & $\begin{array}{c}\text { Sales of NG3 F2 - } \\
\text { simulation }\end{array}$ & $\begin{array}{c}\text { Total sales - } \\
\text { simulation }\end{array}$ \\
\hline 2014 & 0 & 0 \\
\hline 2015 & 7.080 & 7.080 \\
\hline 2016 & 9.659 & 16.739 \\
\hline 2017 & 11.916 & 28.655 \\
\hline 2018 & 12.696 & 41.351 \\
\hline 2019 & 11.092 & 52.443 \\
\hline 2020 & 7.634 & 60.077 \\
\hline 2021 & 4.139 & 64.216 \\
\hline 2022 & 1.865 & 66.081 \\
\hline
\end{tabular}

The results of simulation of the sales of NG2 F2 appliances from Table VII are also shown in the form of a sales curve or lifecycle curve. 


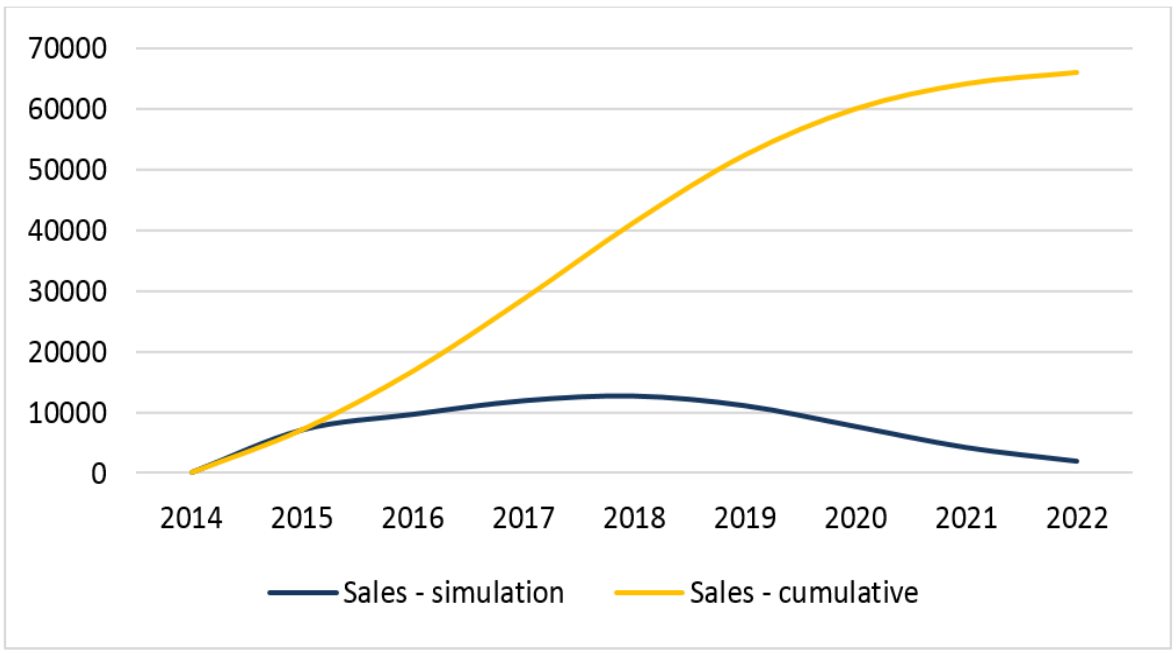

Figure 4: Simulation of the fluctuation of sales of NG3 F2 appliances between 2014 and 2022.

Fig. 4 shows the simulated sales of NG3 F2 appliances by years, from its introduction in 2014 to 2022 when the life span of the appliances is expected to come to an end. According to the simulation, we are currently in a growth stage that should last for another one or two years. In 2018 the sales are supposed to peak, and after 2019 the sales are gradually going to decrease.

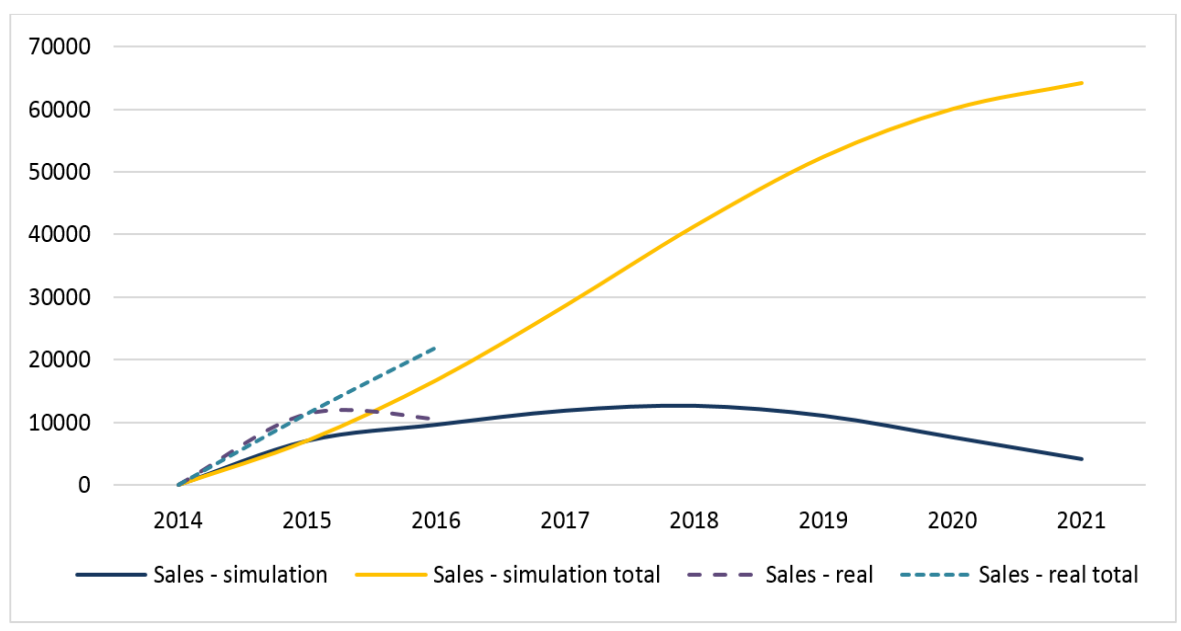

Figure 5: Comparison of real sales quantities with simulated sales quantities for NG3 F2.

Fig. 5 shows the comparison of real sales in 2015 and 2016. We can see that real sales in 2016 deviated significantly from the simulation results. The reason was the accelerated transition between the two generations and increased demand for the new generation appliances (F2), due to the marketing activities that took place on the market. If we look at the results of the simulation for 2016, we can see that the real sales curve came much closer to the simulation of sales and the difference between the values was merely 8 per cent.

\section{CONCLUSION}

Nowadays almost all companies build their brand strength on multi-generation products. It is the task of strategic management to launch new products on time and make sure that the new products achieve the set financial goals. The key role in this is played by different models that can be used to forecast the sales of the products, which is the basis for creating the development strategies of a company. Strategic management must have a clear vision of 
product development. The original model demonstrated in the article and the simulation results are a tool that can help in planning the development strategy.

The results of the simulation of forecasting the lifecycle curve for the NG3 F2 appliances show that the appliances will reach the maturity stage in 2018 and that the platform is still interesting for the buyers. The review of new products that were launched by competition shows that we will need to start development activities on a completely new platform, which will enable new, innovative and interesting solutions for the user. Based on the simulation and the review of the market situation we can make a recommendation that the company should include in its 2017 projects plan the beginning of a conception stage for a new generation of built-in ovens. Due to long-lasting and demanding processes of conception and introduction of a new platform on the market, timely planning of projects is of key importance in the development strategy. It is important that the company's strategic management makes timely and adequate plans for projects and resources in order for the company to maintain or increase its competitive advantage in relation to others in the industry. This is the only way it can ensure a constant cash flow, which is crucial for a company's viability.

\section{ACKNOWLEDGEMENT}

The authors acknowledge the financial support from the Slovenian Research Agency (research core funding No. P2-0190).

\section{REFERENCES}

[1] Karakasic, M.; Zadnik, Z.; Kljajin, M.; Duhovnik, J. (2016). Matrix of function and functionality as a tool in product development process, Technical Gazette, Vol. 23, No. 5, 1295-1300, doi:10.17559/TV-20160609095229

[2] Qi, Y.; Tang, M.; Zhang, M. (2014). Mass customization in flat organization: The mediating role of supply chain planning and corporation coordination, Journal of Applied Research and Technology, Vol. 12, No. 2, 171-181, doi:10.1016/S1665-6423(14)72333-8

[3] Koren, R.; Prester, J.; Buchmeister, B.; Palčič, I. (2016). Do organisational innovations have impact on launching new products on the market?, Strojniški vestnik - Journal of Mechanical Engineering, Vol. 62, No. 6, 389-397, doi:10.5545/SV-JME.2016.3470

[4] Foldes, G. (2009). New product forecasting in the pharmaceutical industry, The Journal of Business Forecasting, Vol. 28, No. 4, 4-11

[5] Sääksjärvi, M.; Lampinen, M. (2005). Consumer perceived risk in successive product generations, European Journal of Innovation Management, Vol. 8, No. 2, 145-156, doi: $10.1108 / 14601060510594675$

[6] Koren, R.; Palčič, I. (2015). The impact of technical and organisational innovation concepts on product characteristics, Advances in Production Engineering \& Management, Vol. 10, No. 1, 2739, doi:10.14743/APEM2015.1.190

[7] Krankel, R. M.; Duenyas, I.; Kapuscinski, R. (2006). Timing successive product introductions with demand diffusion and stochastic technology improvement, Manufacturing \& Service Operations Management, Vol. 8, No. 2, 119-135, doi:10.1287/MSOM.1060.0102

[8] Lin, C.-Y.; Okudan Kremer, G. E. (2014). Strategic decision making for multiple-generation product lines using dynamic state variable models: The cannibalization case, Computers in Industry, Vol. 65, No. 1, 79-90, doi:10.1016/J.COMPIND.2013.07.010

[9] Stevanovic, M.; Marjanovic, D.; Storga, M. (2016). Idea management in product innovation - the empirical research results, Technical Gazette, Vol. 23, No. 5, 1285-1294, doi:10.17559/TV20150603223629

[10] Norton, J. A.; Bass, F. M. (1987). A diffusion theory model of adoption and substitution for successive generations of high-technology products, Management Science, Vol. 33, No. 9, 10691086, doi: $\underline{10.1287 / M N S C .33 .9 .1069}$ 
[11] Mahajan, V.; Muller, E.; Wind, Y. (Eds.), (2000). New-product diffusion models, International series in quantitative marketing, Kluwer Academic Publishers, Boston

[12] Thomas, R. J. (1985). Estimating market growth for new products: an analogical diffusion model approach, Journal of Product Innovation Management, Vol. 2, No. 1, 45-55, doi:10.1111/1540$\underline{5885.210045}$

[13] Bayus, B. L. (1993). High-definition television: assessing demand forecasts for a next-generation consumer durable, Management Science, Vol. 39, No. 11, 1319-1333, doi:10.1287/ MNSC.39.11.1319

[14] Bass, F. M.; Gordon, K.; Ferguson, T. L.; Githens, M. L. (2001). DIRECTV: Forecasting diffusion of a new technology prior to product launch, Interfaces, Vol. 31, No. 3_Supplement, S82-S93, doi:10.1287/INTE.31.3S.82.9677

[15] Mahajan, V.; Sharma, S. (1986). A simple algebraic estimation procedure for innovation diffusion models of new product acceptance, Technological Forecasting and Social Change, Vol. 30, No. 4, 331-345, doi:10.1016/0040-1625(86)90031-4

[16] Morrison, D. G. (1979). Purchase intentions and purchase behavior, Journal of Marketing, Vol. 43, No. 2, 65-74, doi:10.2307/1250742

[17] Jamieson, L. F.; Bass, F. M. (1989). Adjusting stated intention measures to predict trial purchase of new products: a comparison of models and methods, Journal of Marketing Research, Vol. 26, No. 3, 336-345, doi:10.2307/3172905

[18] Palčič, I.; Buchmeister, B.; Polajnar, A. (2010). Analysis of innovation concepts in Slovenian manufacturing companies, Strojniski vestnik - Journal of Mechanical Engineering, Vol. 56, No. $12,803-810$

[19] Leber, M.; Bastič, M.; Buchmeister, B. (2014). The trends in usage and barriers of innovation management techniques in new product development, Strojniski vestnik - Journal of Mechanical Engineering, Vol. 60, No. 6, 382-388, doi:10.5545/sv-jme.2013.1611

[20] Aytac, B.; Wu, S. D. (2011). Modelling high-tech product life cycles with short-term demand information: a case study, Journal of the Operational Research Society, Vol. 62, No. 3, 425-432, doi:10.1057/JORS.2010.89

[21] Bendato, I.; Cassettari, L.; Mosca, M.; Mosca, R.; Rolando, F. (2015). New markets forecast and dynamic production redesign through stochastic simulation, International Journal of Simulation Modelling, Vol. 14, No. 3, 485-498, doi:10.2507/IJSIMM14(3)10.307

[22] Jain, C. L. (2012). Answers to your forecasting questions, The Journal of Business Forecasting, Vol. 31, No. 2, 3

[23] Mahajan, V.; Muller, E.; Bass, F. M. (1990). New product diffusion models in marketing: A review and directions for research, Journal of Marketing, Vol. 54, No. 1, 1-26, doi: $10.2307 / 1252170$

[24] Wu, S. B.; Gu, X.; Wu, G. D.; Zhou, Q. (2016). Cooperative R\&D contract of supply chain considering the quality of product innovation, International Journal of Simulation Modelling, Vol. 15, No. 2, 341-351, doi:10.2507/IJSIMM15(2)CO7

[25] Bass, F. M. (1969). A new product growth for model consumer durables, Management Science, Vol. 15, No. 5, 215-227, doi:10.1287/mnsc.15.5.215

[26] Business Performance Management Singapore, from http:///bmsg.com/, accessed on 29-04-2016 